\title{
Brahim ag Abakada, Amghar des Ajjers
}

M. Vacher

\section{OpenEdition}

Journals

Édition électronique

URL : http://journals.openedition.org/encyclopedieberbere/1833

DOI : 10.4000/encyclopedieberbere.1833

ISSN : 2262-7197

\section{Éditeur}

Peeters Publishers

\section{Édition imprimée}

Date de publication : 1 septembre 1992

Pagination : 1608-1609

ISBN : 2-85744-581-4

ISSN : 1015-7344

\section{Référence électronique}

M. Vacher, «Brahim ag Abakada, Amghar des Ajjers », Encyclopédie berbère [En ligne], 11 | 1992, document B104, mis en ligne le 01 juin 2012, consulté le 25 septembre 2020. URL : http:// journals.openedition.org/encyclopedieberbere/1833; DOI : https://doi.org/10.4000/ encyclopedieberbere.1833

Ce document a été généré automatiquement le 25 septembre 2020.

(c) Tous droits réservés 


\title{
Brahim ag Abakada, Amghar des Ajjers
}

\author{
M. Vacher
}

1 Brahim ag Abakada, plus connu chez les Français sous le nom de Caïd Brahim, est né vers 1885 à Ghat. Son père était un. Oghaghen de la fraction des Kel-Imirho et sa mère une toubbou nommée Mia. Pendant toute sa jeunesse, du fait de l'origine de sa mère, il ne fut pas traité avec considération par son oncle Boubaker ag Legoui et son cousin Khoussini.

2 Aussi, dès qu'il le put, Brahim s'empressa de quitter Ghat pour s'installer dans le Tassili, près de ses imrads, partageant sa vie entre l'Oued Imirho et Aharar. En effet, lors de la répartition de l'hadda, entre les tribus vassales, faite par Ikheroukhen vers 1840 (?), les Kel-Imirho s'étaient vu reconnaître les Kel-Teberen et les Idjeradjerihouen comme celles devant leur « fournir le lait ».

3 Très vite, il prit un grand ascendant sur toutes les tribus du Tassili, grâce à sa finesse d'esprit et à son courage. En 1910, il montait le rezzou de Tahihahout. On a longtemps dit qu'il aurait participé à l'assassinat du Marquis de Mores, en 1896, mais cela n'est guère possible car il n'avait que dix ans à cette date.

4 Vers 1916, à la mort d'Inguedazzen, dernier aménokal Ajjers, avec l'idée de contrebalancer l'influence de Boubakeur ag Legoui qui n'avait pu être intronisé du fait de la guerre et de la coupure entre le territoire français et Ghat, il offrait ses services aux militaires français contre les Sénoussistes tripolitains. Il exigeait d'être chef de goum et de disposer librement d'armes et de munitions. Ses conditions ayant été refusées, quelques semaines après la chute de Djanet, il devint l'un des adversaires les plus actifs de la France.

5 Chef de bande adroit et brave, il livre de durs combats : In-Amedgen, 12-7-16 - Oued Ehan, 6-9-16 - Aïn Zabat, 27-11-16 - Aïn Rerou, 3-12-16 - Base d'Aïn el Hadjaj, 13-2-17 Tanezrouft, 12-5-17.

6 On a prétendu que le guet-apens d'Aïn Guettara (route de Fort-Miribel à In-Salah) où, en février 1918, une section automobile fut anéantie, aurait été son œuvre. Le fait n'a 
pu être établi, mais un de ses lieutenants, Mahdi ould El Hadj Baba (qui finit d'ailleurs première classe, médaillé militaire et retraité à la Compagnie des Ajjers), n’a jamais caché y avoir pris part.

7 Une chose a toujours été reconnue par tous: sitôt les combats terminés, les blessés étaient recueillis et soignés par lui. Dès qu'ils étaient guéris, une escorte leur était fournie et ils étaient renvoyés vers le poste français le plus proche. Après l'évacuation de Fort-Polignac en 1917, l'on raconte que c'est lui qui interdit le saccage du poste, qu'il en ferma la porte à clef (elle avait été oubliée) et mit celle-ci dans sa poche en disant : "Je la redonnerai aux Français, s'ils reviennent ».

En 1919, à la suite de sa soumission à Tarat, au Lieutenant Guillot et au Colonel Sigonney, il reçut le titre d'Amghar des Imrads du Tassili. Après de longues négociations, il obtint pour ses Touaregs :

- que des convois de transport de ravitaillement leur soient réservés.

- des dotations de cartouches de fusils 1874, pour la chasse.

- des engagements comme militaires.

Pour sa part, il avait droit à six goumiers et a un petit traitement.

9 Par la suite, le Capitaine Gay, qui avait succédé en 1933 au Capitaine Duprez, comme chef de l'Annexe des Ajjers, lui fit attribuer chaque mois une dotation de $100 \mathrm{~kg}$ de blé, $15 \mathrm{~kg}$ de sucre, $5 \mathrm{~kg}$ de thé.

Le Caïd Brahim était toujours entouré d'une bande de "pique-assiettes ». L'un des plus rapaces était son demi-frère Djebrin ag Abdallah, mais son secrétaire, Taleb Belkheir et son serviteur de confiance, un noir affranchi nommé Brahim, étaient devenus plus riches que lui.

11 Vers 1925, il avait épousé une femme des Kel-Toberen dont il eu un fils, Doudou. Après le décès de cette femme, il se remaria avec une noble que l'on ne connaissait que sous le nom de la "Noggariaté ». Très violente et jalouse, elle lui faisait publiquement des scènes mémorables car il était grand coureur de jupons. Il ne s'en tirait qu'en payant chaque fois une « amende » (naïls, tissu, tabac à chiquer, etc.).

Durant l'été 1946, la mort, à Fort-Polignac, de sa mère qu'il aimait profondément, le changea et lui donna une nouvelle autorité. Avec elle avaient disparu en effet les humiliations de sa jeunesse et la preuve qu'il était en partie d'ascendance toubou. Certains talebs essayèrent alors de prouver qu'il avait du sang du Prophète dans ses veines...

13 Au fil des années et avec la disparition de ses vieux compagnons de baroud, il s'appuya sur l'autorité morale d'un grand Oghaghen, Mohamed ag Abegouan dit Latrèche, qu'il appelait son oncle.

14 Rallié loyalement au gouvernement français, il est resté fidèle jusqu'à la fin. De 1930 (date de la prise de Ghat par les Italiens) à 1942 (occupation du Fezzan par les Français), il a refusé toutes les offres que lui faisaient les officiers de Hon, Sebbah et Ghat. Quémandeur insatiable, plus pour les autres que pour lui, il s'était fixé entre autres buts, celui de faire engager le maximum de Touaregs comme militaires. Il savait, en effet, qu'un méhariste dans une famille était une source de bien-être et d'indépendance matérielle pour celle-ci.

15 Nommé Conseiller général lors de la création de la sous-préfecture des Ajjers en 1960, il est mort en juillet 1962, dans les bras de son grand ami, le Commandant Rossi, sous- 
préfet de Djanet, en lui disant : «Tu vois, Rossi, je pars, j’ai tenu parole depuis l'aman de 1919, de ne plus tirer sur les Français ».

16 Avec lui disparaissait un des derniers guerriers du Tassili qui avaient combattu contre les méharistes du Groupe mobile des Ajjers, que Joseph Peyré appelait «Ceux de la Compagnie des ergs et des paysages lunaires ».

INDEX

Mots-clés : Biographie, Histoire contemporaine, Nomadisme, Sahara 